\title{
The IMPACT OF BiOLOGICAL PSYCHIATRY ON THE LAW: EVIDENCE, BLAME, AND SOCIAL SOLIDARITY
}

\author{
JENNIFER A. CHANDLER ${ }^{*}$
}

\begin{abstract}
This article considers the history of biological understanding of mental disorder, and explores the impact of today's dominant neuroscientific approach on the law. The author argues that this approach subtly affects legal rules and practices, and that these socio-legal effects will likely be enhanced by the increasingly sophisticated use of neuroscience in biological psychiatry. The author illustrates the impact of the neurobiological model using five areas of law: evidence of mental states, the definition of disability in human rights law, criminal responsibility, the regulation of brain interventions, and the regulation of reproductive technologies.
\end{abstract}

TABle OF CONTENTS

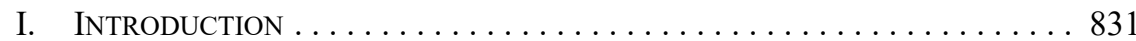

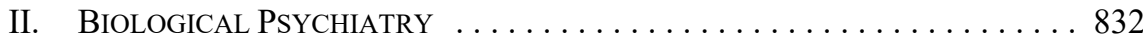

III. BRain IMAGing AND OBJeCtive EvidenCE Of Mental StATES . . . . . . 834

IV. Defining Disability: Social Solidarity and Human Rights . . . . 837

V. Blame AND CRIMINAL RESPONSIBILITY $\ldots \ldots \ldots \ldots \ldots \ldots \ldots . \ldots 41$

VI. THE REGULATION OF BRAIN INTERVENTIONS:

Mind-BRAIn DUALISM $\ldots \ldots \ldots \ldots \ldots \ldots \ldots \ldots \ldots \ldots . \ldots \ldots$

VII. REgUlATION OF RePRODUCTIVE TEChNOLOGIES:

THE "New EugEnics"? . . . . . . . . . . . . . . . . . . . . . . . . 845

VIII. CONCLUSION ................................ 848

\section{INTRODUCTION}

The relationship between the mind and body remains one of the most fascinating and longenduring puzzles facing philosophy, medicine, and many other disciplines. The nature of consciousness and subjective mental experiences, and their relationship to neurological structures and functions remain mysterious. The law, however, is not particularly concerned with the relationship between mental experiences and the physical brain even though legal institutions are involved every day in practical problems related to human behaviour and mental states. For example, in assigning blame and responsibility, the law is more interested in the functional effects of mental disorder than in whether it is understood as a psychological disturbance of the mind or a physiological disturbance of the brain and body. In other words, the law is more interested in a mental disorder's effect on capacity than on its causes - whether biological, psychological, or social. In this article, however, I suggest that the dominant frame of reference adopted to understand mental disorder has a range of subtle effects on legal rules and practices, and that the increasingly sophisticated use of neuroscience in biological psychiatry is likely to enhance these socio-legal effects.

The article starts with a brief overview of biological psychiatry, showing that biological understandings of mental disorder have ancient origins in Western thought, but have ebbed 
and flowed in popularity over time, coexisting sometimes acrimoniously with other models of mental disorder. This section presents and explains today's dominance of neuroscientific approaches within a historical context. I then suggest that the neurobiological model of mental disorder will affect the law in five areas: evidence of mental states, the definition of disability in human rights law, criminal responsibility, the regulation of brain interventions, and the regulation of reproductive technologies. Some of these are admittedly speculative, but are advanced as suggestions for further attention as neuroscientific research proceeds and is incorporated within social institutions and practices, such as the law.

\section{Biological Psychiatry}

Over the years, the nature and causes of mental illnesses have been framed in supernatural, psychosocial, and biological terms. The dominant paradigm is now that of biological psychiatry, an approach that understands mental experiences primarily in terms of the biological functioning of the nervous system. ${ }^{1}$ It may seem that the biological approach is a modern idea, but nothing could be further from the truth. The fourth century BC Hippocratic text entitled "On the Sacred Disease" articulated a naturalistic biological explanation of mental states. Rather than resulting from divine punishment, the symptoms of mental disorder were the result of imbalances in bodily humours. ${ }^{2}$

\footnotetext{
Men ought to know that from nothing else but the brain come joys, delights, laughter and sports, and sorrows, griefs, despondency, and lamentations.... And by the same organ we become mad and delirious, and fears and terrors assail us, some by night, and some by day, and dreams and untimely wanderings, and cares that are not suitable, and ignorance of present circumstances, desuetude, and unskilfulness. All these things we endure from the brain, when it is not healthy, but is more hot, more cold, more moist, or more dry than natural, or when it suffers any other preternatural and unusual affection. And we become mad from its humidity. ${ }^{3}$
}

While supernatural explanations of mental illness are now uncommon, the tension between biological and psychological theories has existed since the very beginning of psychiatry as a medical discipline, in the late nineteenth century.

Psychiatry has always been torn between two visions of mental illness. One vision stresses the neurosciences, with their interest in brain chemistry, brain anatomy, and medication, seeing the origin of psychic distress in the biology of the cerebral cortex. The other vision stresses the psychosocial side of patients' lives,

1 German E Berrios \& Ivana S Markova, "Conceptual Issues" in Hugo D'haenen, JA den Boer \& P Willner, eds, Biological Psychiatry, vol 1 (Chichester: John Wiley \& Sons, 2002) 3 at 3; John Gach, "Thoughts Toward a Critique of Biological Psychiatry" in Edwin R Wallace \& John Gach, eds, History of Psychiatry and Medical Psychology (New York: Springer, 2008) 685 at 685; Edward Shorter, A History of Psychiatry: From the Era of the Asylum to the Age of Prozac (New York: John Wiley \& Sons, 1997) at 26.

2 Roy Porter, Madness: A Brief History (New York: Oxford University Press, 2002) at 41; Bennett Simon, "Mind and Madness in Classical Antiquity" in Edwin R Wallace \& John Gach, eds, History of Psychiatry and Medical Psychology (New York: Springer, 2008) 181 at 181; Theodore Millon, Masters of the Mind: Exploring the Story of Mental Illness from Ancient Times to the New Millennium (Hoboken: John Wiley \& Sons, 2004) at 16.

3 Hippocrates, "On the Sacred Disease," translated by Francis Adams (MIT Internet Classics Archive, 400 BCE), online: <classics.mit.edu/Hippocrates/sacred.html>. 
attributing their symptoms to social problems or past personal stresses to which people may adjust imperfectly. 4

In his History of Psychiatry, Shorter charts this tension between biological and psychological theories, identifying two main periods during which biological approaches were in the ascendancy, separated by the early to mid-twentieth century era of Freudian psychoanalysis. ${ }^{5}$ The second wave, emerging in the $1970 \mathrm{~s}$, was fuelled by psychiatric genetics research involving large twin and adoptee studies and the discovery of effective psychiatric drugs such as the anti-psychotic drug chlorpromazine. ${ }^{6}$ Walter suggests that we are in the midst of a third wave of biological psychiatry, which began in the 1980s, driven by progress in molecular neuroscience, and the development of cognitive neuroscience, neuroimaging, and other techniques that enable the study of the interactions between genetics, experience, and the environment. ${ }^{7}$ In Walter's view, these developments are together leading to a much more complex and sophisticated picture of brain organization and the neurobiological changes associated with psychiatric disorders. "The underlying model is that of systems medicine, understood as an interdisciplinary field of study that looks at the dynamic systems of the human body as part of an integrated whole, incorporating biochemical, physiological, and environmental interactions." 8

In Walter's account, this third wave of biological psychiatry is an inclusive one that can incorporate multiple levels of information (examples include genetic, molecular, cellular, circuit, physiological, behavioural, and patients' self-reported experience), can allow for multiple and complex causations of mental disorder (including, biological, psychosocial, and cultural mechanisms), and does not entail that narrowly biological approaches (such as, psychopharmacology) are necessarily the best therapies. ${ }^{9}$

This being said, some may be skeptical about the apparent inclusiveness and neutrality regarding therapeutic modalities of this latest approach to biological psychiatry. There is evidence that clinicians are more likely to favour pharmacotherapy when patients' conditions are framed in biological, as opposed to psychosocial, terms. ${ }^{10}$ Furthermore, some may harbour concerns that the apparently inclusive new biological psychiatry constitutes "lip service" to the mental or subjective experiences of patients or that it encourages inefficient allocation of resources to neurobiological approaches at the expense of addressing known psychosocial contributions to the development or maintenance of psychiatric disorders. ${ }^{11}$

Another concern that may exist with biological approaches to psychiatry is the unintended psychological impact of biological causal explanations on the attitudes of both clinicians and patients. Biological explanations for mental illnesses seem to encourage the belief that symptoms are immutable, leading to prognostic pessimism and a reduced sense among

Shorter, supra note 1 at 26.

Ibid.

Ibid.

Henrik Walter, "The Third Wave of Biological Psychiatry" (5 September 2013) Frontiers in Psychology 1 at 2.

Ibid.

Ibid.

Matthew S Lebowitz \& Woo-kyoung Ahn, "Effects of Biological Explanations for Mental Disorders on Clinicians' Empathy” (2014) 111:50 Proceedings National Academy Science US 17786.

Walter, supra note 7 at 5; Gach, supra note 1 at 688. 
patients of personal ability to regulate symptoms, raising the risk of self-fulfilling beliefs in the immutability of mental illness. ${ }^{12}$ There is evidence, however, that educational interventions emphasizing the malleability of biological factors involved in mental illnesses may help to counteract these reactions. ${ }^{13}$ It is not just patients who may be affected by biological causal explanations of mental disorders, and there is considerable evidence that links these biological causal accounts to increased public perceptions of dangerousness of people with mental illness and the desire to limit social interactions with them. ${ }^{14}$ Furthermore, it appears that clinicians' level of empathy for their patients is reduced by biological explanations of mental disorders, which is troubling given the importance of clinician empathy for the therapeutic relationship. ${ }^{15}$ Perhaps, as with the beneficial effects of educational interventions with patients, public and clinical education might overcome these potentially harmful side effects of biological causal accounts of mental disorders more broadly.

Research on mental health stigma is actively exploring the ideological impact of biological psychiatry on social behaviour and attitudes, and in the therapeutic context. The purpose of the present article is to broaden the field of view to explore these same ideological effects in another important field of social behaviour, the law and legal decision-making. As the following sections suggest, there is reason to think that there may be fascinating and subtle effects of biological explanations of mental states and behaviours throughout the law.

\section{BRAIN IMAGING AND OBJECTIVE EVidence of Mental States}

Courts are frequently intensely interested in subjective mental states. Yet, mental states such as the experience of pain, memories, deception, or sexual interests are private, directly accessible only to the person experiencing them. Yet, their existence is relevant to legal questions such as the quantum of damages to be awarded in personal injury litigation, entitlement to disability insurance benefits, the value of testimony about past experiences and observations, as well as forensic risk assessment in the criminal context. A witness's veracity is frequently questioned because of the existence of powerful incentives to claim a particular mental state in court. As a result there is an omnipresent risk of accepting false claims as well as rejecting true claims.

One of the intriguing developments in recent years has been the rise of functional magnetic resonance imaging (fMRI), which detects patterns of blood flow in the brain. Relying on the assumption that these patterns of blood flow reflect brain activity, researchers are actively examining whether there are neurological "correlates" for particular mental experiences that might allow one to infer, from a particular pattern of brain activation, whether a person is experiencing a particular mental state. At present, it is not clear if or

12 Matthew S Lebowitz \& Woo-kyoung Ahn, "Emphasizing Malleability in the Biology of Depression: Durable Effects on Perceived Agency and Prognostic Pessimism" (2015) 71 Behaviour Research \& Therapy 125; Nicholas R Farrell, Aaron A Lee \& Brett J Deacon, "Biological or Psychological? Effects of Eating Disorder Psychoeducation on Self-Blame and Recovery Expectations Among Symptomatic Individuals" (2015) 74 Behaviour Research \& Therapy 32.

Farrell, Lee \& Deacon, ibid.

Lebowitz \& Ahn, supra note 12.

Ibid. 
when this research will furnish evidence of mental states like pain, deception, or memory that will satisfy tests of evidentiary admissibility.

Nevertheless, attempts have been made to introduce fMRI evidence of mental states in court. One of the first attempts to reach the courts has been fMRI-based lie detection. Based on research suggesting that deliberate deception can be identified by patterns of brain activation, several litigants have now attempted to submit in court fMRI evidence about a witness's veracity. ${ }^{16}$ These efforts have so far been unsuccessful, as courts have not considered the technique to meet the standards for the admissibility of novel scientific evidence. One problem is whether tests on laboratory subjects can reliably be generalized to the very different "real world" situation of an accused person. ${ }^{17}$ Another is that the possibility that a person may be able to defeat the fMRI lie detection test using deliberate countermeasures. ${ }^{18}$

Another active area of research concerns memory, and there are now multiple studies in which researchers are able to distinguish certain types of true and false memories using fMRI and electroencephalography (EEG) under laboratory conditions. ${ }^{19}$ Given the known frailties of eyewitness memory and the risk that memory errors may lead to wrongful convictions, ${ }^{20}$ a technology that would help to detect when eyewitness memory is wrong would be useful. The research so far cannot be safely generalized to the real world contexts at issue in the courtroom, although some leading experts predict that future advances in the neuroimaging technology and analysis will eventually address the problems that currently preclude its use. ${ }^{21}$

Another potential area for the detection of mental states relates to sexual interests, which form part of the risk assessment often at issue in criminal sentencing decisions involving sex offenders. At present, phallometry (or penile measurement to detect sexual arousal in response to sexual stimuli) is used in Canada for treatment and forensic risk assessment. ${ }^{22}$ The SORAG (Sex Offender Risk Appraisal Guide) is an actuarial forensic risk assessment tool that is used to assess sex offenders, which includes a range of risk factors including phallometric results showing "deviant sexual interests." ${ }^{23}$ Researchers are now reporting that it is possible to distinguish between men with pedophilic and non-pedophilic sexual interests using fMRI techniques that measure brain responses to images of naked men, women, and

16 Wilson v Corestaff Services LP, 900 NYS (2d) 639 (Sup Ct 2010); United States v Semrau, 693 F (3d) 510 (6th Cir 2012).

17 Henry T Greely, "Neuroscience, Mindreading, and the Courts: The Example of Pain" (2015) 18:2 J Health Care L \& Pol'y 171.

18 Giorgio Ganis et al, "Lying in the Scanner: Covert Countermeasures Disrupt Deception Detection by Functional Magnetic Resonance Imaging" (2011) 55 NeuroImage 312.

19 Daniel L Schacter \& Elizabeth F Loftus, "Memory and Law: What Can Cognitive Neuroscience Contribute?" (2013) 16:2 Nature Neuroscience 119.

20 The Innocence Project investigated the causes of wrongful convictions revealed by DNA exonerations. Eyewitness misidentification was the most frequently cited contributing cause of the wrongful conviction. See Innocence Project, “Eyewitness Misidentification,” online: <www.innocenceproject.org/ causes/eyewitness-misidentification/>; Jon B Gould \& Richard A Leo, "One Hundred Years Later: Wrongful Convictions After a Century of Research" (2010) 100:3 J Crim L \& Criminology 825.

$21 \quad$ Schacter \& Loftus, supra note 19; Nicole-Simone Werner, Sina Kuhnel \& Hans J Markowitsch, "The Neuroscience of Face Processing and Identification in Eyewitnesses and Offenders" (2013) 7 Frontiers in Behavioural Neuroscience 1 at 8.

22 Michael S Purcell, Jennifer A Chandler \& J Paul Fedoroff, "The Use of Phallometric Evidence in Canadian Criminal Law” (2015) 43:2 J American Academy Psychiatry \& L 141.

23 Vernon L Quinsey, "Sex Offender Risk Appraisal Guide (SORAG)" in Brian L Cutler, ed, Encyclopedia of Psychology and Law (Thousand Oaks: SAGE Publications, 2008) vol 2 at 729; Purcell, Chandler \& Fedoroff, ibid. 
children. ${ }^{24}$ Most recently, Ponseti and colleagues have reported that they can discriminate between men with sexual interests in children versus adults, by looking at the brain response to images of the faces alone, which is preferable given the ethical concerns and legal barriers to using naked images of children in such tests. They note that their subjects admitted their sexual preferences, and so it was not possible to determine whether countermeasures could defeat this technique.

Pain is another private experience not accessible to others, and one that is of great importance in civil liability as well as workers' compensation and disability insurance claims. In the case of chronic pain conditions, in which pain persists long after physical injuries have healed, the lack of some sort of visible reason for the pain combined with the legal incentive to claim pain leads to suspicion of malingering. Even if a plaintiff's claim of pain is believed, defendants and clinicians sometimes take the position that chronic pain conditions are psychogenic (in other words, emerging for psychological reasons). In these cases, the challenge facing claimants is one of causation, as defendants may argue that the plaintiff had a "crumbling skull," meaning that the psychogenic condition was a response in a vulnerable person to any number of stressful life events and would have occurred regardless of the defendants' actions. ${ }^{25}$ While fMRI techniques to detect pain would not answer this second problem for claimants, attempts are now being made to use neuroimaging to address the first problem: suspicion of malingering. Although neuroimaging techniques appear to be effective at detecting acute pain caused in the laboratory in healthy volunteers, it is a different matter to detect chronic pain. ${ }^{26}$ As a result, neuroimaging techniques do not appear to be sufficiently reliable to be used as objective evidence of pain in a courtroom. Despite this, companies are already offering fMRI testing to detect the neurological signatures of pain. ${ }^{27}$ As Sara Reardon recounts in a recent news feature for Nature, this evidence appears to be influencing out of court settlements in civil litigation. ${ }^{28}$

The use of fMRI to draw inferences about mental states of specific individuals is currently subject to a variety of limitations, which may limit its uptake for legal purposes. ${ }^{29}$ If it does eventually offer evidence that meets tests of admissibility, a range of concerns arise. One possible risk is that people may feel pressured to undergo these tests. For example, the failure to supply this evidence might be taken to suggest that a mental state such as pain is being faked. ${ }^{30}$ Another concern specific to pain detection is the possibility that it might be required

Jorge Ponseti et al, "Assessing Paedophilia Based on the Haemodynamic Brain Response to Face Images" (2015) 17:1 World J Biological Psychiatry 39; Christine Wiebking \& Georg Northoff, "Neuroimaging in Pedophilia" (2013) 15 Current Psychiatry Reports 350. 25 See e.g. Hunt v Ugre, 2012 BCSC 1704, 2012 BCSC 1704 (CanLII); Michael Finch, "Law and the
Problem of Pain" (2005) 74:2 U Cin L Rev 285; Shirley A Pate, "Litigating Chronic Pain Syndrome in the Canadian Court System" (1996) 5:2 Health L Rev 19.

26 AC Pustilnik, "Imaging Brains, Changing Minds: How Pain Neuroimaging Can Inform the Law" (2014) 66:5 Ala L Rev 1099 at 1120-21, citing Tor D Wager et al, "An fMRI-Based Neurologic Signature of Physical Pain" (2013) 368:15 New Eng J Med 1388.

27 Sara Reardon, "Neuroscience in Court: The Painful Truth" Nature (2 March 2015), online: $<$ www.nature.com/news/neuroscience-in-court-the-painful-truth-1.16985>; Pustilnik, ibid.

Reardon, ibid.

Martha J Farah "Brain Images, Babies, and Bathwater: Critiquing Critiques of Functional Neuroimaging" (2014) 44 Hastings Center Report S19.

Reardon, supra note 27; Natalie Salmanowitz, "The Case for Pain Neuroimaging in the Courtroom: Lessons from Deception Detection" (2015) JL \& Biosciences 1; Shaun Cassin, "Eggshell Minds and Invisible Injuries: Can Neuroscience Challenge Longstanding Treatment of Tort Injuries?" (2013) 50:3 Hous L Rev 929; Greely, supra note 17. 
to access certain prescription medications or insurance coverage. ${ }^{31}$ Another important issue if this evidence proves admissible is distributive justice, given that the cost of the test would make it inaccessible to many.

A broader question posed by the use of neuroimaging to find "objective" evidence of mental states is that it sets up a possible contest between subjective mental experiences and objective brain states. It is possible that the two may diverge, leading to a situation in which a person's mental experience is at odds with what the fMRI results say it should be. For example, a person may subjectively remember something, only to be told that the brain imaging indicates that it is a false memory. In these circumstances, a contest of epistemic authority arises. Should the subjective experience be taken as reality, or should the objective brain evidence be taken to have successfully revealed that a person is delusional or lying? Some people, presented with this situation may refuse to believe the objective brain evidence, but others may instead come to doubt their own experiences. There are costs to doubting oneself, one of which might be vulnerability to suggestion, misinformation, and manipulation by others. ${ }^{32}$

\section{DEFINING DisabiLity: SOCIAL SOLIDARITY AND HUMAN RIGHTS}

The prevailing beliefs about the causes of a person's behaviour or condition affect feelings of social solidarity and willingness to help and protect the person. In essence, we are more likely to accept and protect people with disfavoured attributes and behaviours if those characteristics are perceived to be outside their causal control. As explained below, biological explanations of a behavioural problem increase the perception that it falls outside a person's control. In this way, biological psychiatry may affect fundamental concepts in the area of human rights, where perceptions of control over one's condition and behaviour may affect the willingness to recognize it as a disability for the purposes of disability benefits and anti-discrimination protection under human rights law.

Social psychologists have long been interested in the impact of judgments about the causes of a person's behaviour or condition on social responses to that person. ${ }^{33}$ In particular, attribution theory looks at three dimensions of causal attributions: the locus, controllability, and stability of the cause. ${ }^{34}$ Locus refers to whether or not the cause is internal to an actor (for instance, genetics, character, or personal decisions) or external to the actor (for example, bad luck or societal discrimination).

Controllability refers to the degree of control a person has over a particular cause. This is where biological causes may diverge from other types of internal causes such as those

Reardon, supra note 27.

Saskia Van Bergen et al, "Memory Distrust and Acceptance of Misinformation" (2010) 24 Applied Cognitive Psychology 885.

33 Jeremiah Garretson \& Elizabeth Suhay, "Scientific Communication About Biological Influences on Homosexuality and the Politics of Gay Rights" (2016) 69:1 Political Research Q 1 at 9.

34 Bernard Weiner, "On Sin Versus Sickness. A Theory of Perceived Responsibility and Social Motivation” (1993) 48:9 Amercian Psychologist 957; Bernard Weiner, Danny Osborne \& Udo Rudolph, "An Attributional Analysis of Reactions to Poverty: The Political Ideology of the Giver and the Perceived Morality of the Receiver" (2011) 15:2 Personality \& Social Psychology Rev 199. 
related to character or values. Some types of biological causes are apt to be interpreted as falling outside a person's control (for example, genes), such that states or behaviours understood as biologically caused are less likely to attract blame. ${ }^{35}$ A further layer complicates the relationship between control and blame, however. Even if a person has lost the ability to control a biological condition and so is not blamed for its continuation (due to a lack of "offset controllability"), the person may still be blamed because of perceived control over the development of the condition (due to perceived "onset controllability"). Conversely, even if a person is not responsible for the onset of a condition, the person may be blamed for the failure to take steps within his or her control to address it. ${ }^{36}$

The third dimension - stability - considers whether a cause is immutable or instead is amenable to change over time. Some biological causes such as genetics are understood as immutable, while others are considered modifiable.

Another important dimension in understanding the impact of a given causal explanation of a particular behaviour or condition is the strength of that causal contribution. For example, some causes are understood as powerful — invariably leading to a given outcome — while others are weaker predisposing factors that may be counterbalanced or supplemented by other causal influences.

The reframing of historically stigmatized human characteristics as matters of unchosen and immutable biology is correlated with reduced blame and increased social solidarity. The shift from environmental or personal choice accounts of sexual orientation to biological explanations in the 1990s was framed in the US media as likely to have socially progressive effects such as reducing blame and increasing acceptance and support for human rights protection. ${ }^{37}$ Dissenters were concerned that the biological explanations would instead generate eugenic practices by expecting parents or increase pressure to medicalize and "cure" homosexuality. ${ }^{38}$ Garretson and Suhay's recent study of a set of American public opinion surveys from the 1980s, 1990s, and 2000s explored the relationship between the rise in the 1990s of biological explanations of sexual orientation, attitudes to whether sexual orientation is innate or chosen, and support for gay rights. They conclude that

\footnotetext{
in the wake of the American media's focus in the early 1990s on biological causes of homosexuality and their progressive implications, public opinion in the United States changed in substantial ways ... Americans who believed homosexuality to be innate shortly after the spike in 'born gay' messages became more progressive on gay rights over time, suggesting that altered causal attributions contributed to progressive changes in societal attitudes toward lesbians and gays during the $1990 \mathrm{~s}^{39}$
}

Garretson \& Suhay, supra note 33.

Patrick W Corrigan, "Mental Health Stigma as Social Attribution: Implications for Research Methods and Attitude Change" (2000) 7:1 Clinical Psychology: Science \& Practice 48.

Garretson \& Suhay, supra note 33.

Ibid.

Ibid at 9. 
The explanation of the linkage between changed attitudes and biological causal explanations of homosexuality is complex, however. Some have suggested that moral judgments of homosexuality might instead explain the adoption of particular causal accounts. ${ }^{40}$

In any event, the deliberate adoption of biological causal accounts of other stigmatized groups or conditions has been explored as a means to reduce stigma and discrimination. The brain disease model of mental illnesses such as schizophrenia has been deliberately invoked in an attempt to reduce stigma, although unfortunately this type of message may reduce one component of stigma, namely, blame, while increasing others such as, pessimism about recovery, stereotypes about unpredictability and dangerousness, and social rejection or "othering.," The brain disease model has also been deployed in the context of addiction with similarly mixed results in reducing stigma. ${ }^{42}$

In addition to effects on social stigma, biological causal accounts of socially disfavoured behaviours may also affect the law. Proponents of the brain disease model of addiction argue that the widespread adoption of this model enabled the passage in 2008 of mental health parity legislation in the US requiring that medical insurance cover the costs of addiction treatment. ${ }^{43}$ The model of addiction as a chronic brain disease is now being expanded to other forms of compulsive behaviours including pathological gambling. Pathological gambling was formerly classified in the fourth edition of the Diagnostic and Statistical Manual of Mental Disorders as an "impulse-control disorder" ${ }^{44}$ but was recently reclassified in the fifth edition, the DSM-5, within the section on "substance-related and addictive disorders." 45 The notes on the section indicate that gambling disorder has been added because of "evidence that gambling behaviors activate reward systems similar to those activated by drugs of abuse and produce some behavioral symptoms that appear comparable to those produced by the substance use disorders." 46 Tovino suggests that this neurobiologically-driven reclassification of pathological gambling may have legal implications in states like Nevada, which exclude health insurance coverage for "impulse control disorders" but make an exception for substance-related conditions (drug and alcohol use disorders). ${ }^{47}$ She argues that the claim that pathological gambling should not be treated like an "impulse control disorder" but instead like a substance-related disorder has been strengthened by the recent reclassification of pathological gambling as a form of addictive behaviour in the DSM-5.

37:4 Policy Studies J 669.

Patrick W Corrigan \& Amy C Watson, "Stop the Stigma: Call Mental Illness a Brain Disease" (2004) 30:3 Schizophrenia Bulletin 477; Aaron A Lee et al, "Genetic Attributions and Mental Illness Diagnosis: Effects on Perceptions of Danger, Social Distance, and Real Helping Decisions" (2014) 49 Social Psychiatry \& Psychiatic Epidemiology 781; Erlend P Kvaale, William H Gottdiener \& Nick Haslam, "Biogenetic Explanations and Stigma: A Meta-Analytic Review of Associations Among Laypeople" (2013) 96 Social Science \& Medicine 95.

$42 \quad$ Bernice Pescosolido et al, "A Disease Like Any Other'? A Decade of Change in Public Reactions to Schizophrenia, Depression, and Alcohol Dependence" (2010) 167:11 American J Psychiatry 1321; Nora D Volkow \& George Koob, "Brain Disease Model of Addiction: Why Is It So Controversial?" (2015) 2:8 Lancet Psychiatry 677.

43 Volkow \& Koob, ibid; Ken Roy \& Michael Miller, "Parity and the Medicalization of Addiction Treatment" (2010) 42:2 J Psychoactive Drugs 115. American Psychiatric Association, Diagnostic and Statistical Manual of Mental Disorders, 4th ed (Arlington: APA, 2000), s 312.31.

45 American Psychiatric Association, Diagnostic and Statistical Manual of Mental Disorders, 5th ed (Arlington: APA, 2013), s 312.31.

Ibid at 481 .

$47 \quad$ Stacey A Tovino, "Will Neuroscience Redefine Mental Injury? Disability Benefit Law, Mental Health Parity Law, and Disability Discrimination Law" (2015) 12:2 Indiana Health L Rev 695. 
In recent work, I have examined the hypothesis that neurobiological accounts of problematic behaviours would affect human rights law by altering the scope of the legal definition of disability, or by limiting the scope of the protection available where the condition is accepted as a disability. ${ }^{48}$ The definition of disability is important as it sets the scope of entitlement to disability benefits, and the extent of protection from discrimination in employment, among other spheres of social activity. Consistent with the attribution theory described above, the case law reveals a reluctance to accept behavioural conditions that are perceived to be within the control of the claimant as protected disabilities.

The case law also reveals attempts in some contexts to frame problematic behavioural conditions as brain disorders. For example, employees dismissed for stealing from their employers have attempted to raise claims of disability discrimination based on the proposed disability of pathological gambling disorder. In these cases, they have argued for less severe disciplinary measures or accommodation of their disability by, for example, reassigning the employee to a position where theft is impossible. These cases are difficult for claimants, as adjudicators often doubt that the claimant's loss of self-control was sufficient to remove responsibility. ${ }^{49}$ For example, in Re Manitoba and MGEU (Leslie), the arbitration panel doubted that gambling addiction made the decision to steal involuntary, despite evidence that gambling addictions "hijack the brain." 50

The importance of a finding of lack of control in establishing a behavioural condition as a disability is also revealed in the cases dealing with nicotine addiction. Even though addiction to nicotine is medicalized, some courts have refused to recognize it as a disability entitled to protection from discrimination on the basis that it is "a temporary condition that many people voluntarily overcome, albeit with varying degrees of difficulty related to the strength of their will to discontinue smoking." ${ }^{.51}$ Another court found that nicotine addiction was a disability, citing evidence that nicotine was as addictive as cocaine or heroin, and that smoking was a more direct method of delivering a drug to the brain than injecting it into the arm. $^{52}$

In the different context of a recent class action lawsuit against tobacco companies, the experts engaged in a battle over whether nicotine dependence should be viewed as a "brain disease." ${ }^{, 53}$ This was an important point in establishing liability because, if the claimants retained some self-control, then they would be solely or partly responsible for the health consequences of smoking if they persisted despite knowing it was harmful. The judge ultimately concluded that that "[n]icotine affects the brain in a way that makes continued exposure to it strongly preferable to ceasing that exposure. In other words, although it can

Jennifer A Chandler, "The Impact of Neuroscience in the Law: How Perceptions of Control and Responsibility Affect the Definition of Disability" in Judy Illes \& Sharmin Hossain, eds, Neuroethics: Defining the Issues in Theory, Practice, and Policy, 2nd ed (Oxford: Oxford University Press, forthcoming).

49 Re Canada Safeway Ltd and Retail, Wholesale and Department Store Union (sub nom MacNeill) (1999), 82 LAC (4th) 1 (Sask Labour Arbitration).

[2005] MGAD No 14 (QL).

McNeill v Ontario (Ministry of the Solicitor General and Correctional Services) (1998), 126 CCC (3d) 466 (Ont Sup Ct). See also R v Ample Annie’s Itty Bitty Roadhouse, [2001] OJ No 5968 (QL) (Sup Ct J); Yellowknife (City of) $v$ Denny, 2004 NWTTC 2, 2004 NWTTC 2 (CanLII).

$52 \quad$ Cominco Ltd $v$ United Steelworkers of America, Local 9705, [2000] BCCAAA No 62 at para 180.

53 Létourneau v JTI-MacDonald Corp, 2015 QCCS 2382, 20 CCLT (4th) 1 at paras 173, 175. 
vary from individual to individual, nicotine creates dependence. That is the point." ${ }^{, 54}$ The invocation of neurobiological explanations in these cases seems to produce a more sympathetic response to smokers, although the level of sympathy may vary by legal context. Courts may be more willing to find for smokers against tobacco companies, which are profiting from the alleged addiction, than for smokers against employers, who are being asked to accommodate an alleged addiction.

Although it is difficult to draw firm conclusions about the impact of biological explanations of compulsive behaviours from the fairly small number of available cases, the patterns are interesting. Future research looking at legal responses to current attempts to frame behaviours within the brain disease model of addiction, including Internet, sex, and food addictions, will be useful to explore this pattern further.

\section{BLAME AND CRIMINAL RESPONSIBILITY}

The use of biological causal accounts of behaviour to deflect moral blame by suggesting a lack of control may also affect our practices of criminal justice. The question of capacity is central to criminal responsibility. The standard for exculpation set out in section 16 of the Criminal Code ${ }^{55}$ is very high, excluding most cases in which mental disorder is a contribution to the commission of a crime. However, less severe degrees of impaired capacity are often considered at the stage of sentencing a convicted offender. The fundamental principle of sentencing is that a sentence must be proportionate to the gravity of the offence and the degree of responsibility of the offender. Diminished capacity due to mental disorder is frequently taken to reduce the degree of moral blameworthiness and so serves as a mitigating factor in deciding on sentence. ${ }^{56}$ However, at the same time, where prospects for successful treatment and rehabilitation are considered poor and a person is judged to be dangerous, mental disorder may instead lead to a longer sentence because public safety via incapacitation is also an objective of sentencing.

In recent years, there has been a considerable amount of attention paid to biological explanations of mental disorders associated with criminal offending and whether this should affect our judgments of moral responsibility. For example, Glenn, Raine, and Laufer argue that evidence that brain regions critical for emotional and moral capacity are impaired in psychopaths means that those severely affected should not be held criminally responsible for their antisocial actions. ${ }^{57}$ Evidence that an offender possessed a gene associated with impulsive aggression has also resulted in lowered sentences in a number of Italian cases. ${ }^{58}$ Some have argued that evidence of the neurobiological causes of behaviour call into question our practices of punishment based on moral blame, and that we should move to a system

Ibid at para 179 .

Criminal Code, RSC 1985, c C-46.

Clayton C Ruby, Sentencing, 6th ed (Markham: LexisNexis, 2004), s 5.246.

Andrea L Glenn, Adrian Raine \& William S. Laufer, "Is It Wrong to Criminalize and Punish Psychopaths?" (2011) 3 Emotion Rev 302.

M Farisco \& C Petrini, "The Impact of Neuroscience and Genetics on the Law: A Recent Italian Case" (2012) 5 Neuroethics 317. 
based solely on consequentialist objectives such as deterrence, rehabilitation, and incapacitation. ${ }^{59}$

Intuitively, we want to punish those people who truly deserve it, but whenever the causes of someone's bad behaviour are made sufficiently vivid, we no longer see that person as truly deserving of punishment. This insight is expressed by the old French proverb: 'to know all is to forgive all'. It is also expressed in the teachings of religious figures, such as Jesus and Buddha, who preach a message of universal compassion. Neuroscience can make this message more compelling by vividly illustrating the mechanical nature of human action. $^{60}$

This debate, which becomes rapidly embroiled within the ancient philosophical problems of whether we have free will, and whether the concept of moral responsibility necessarily relies upon the existence of free will, continues to roll onward. In some ways these recent genetic and neurobiological challenges to punishment based on moral blame are updated versions of suggestions such as that of Lady Barbara Wootton in the 1960s. Lady Wootton suggested to abandon retributivism in favour of a purely preventive role for criminal justice, one that abandons useless or incoherent concepts of moral responsibility and focuses on rehabilitative treatment or, failing that, incapacitation. ${ }^{61}$

Despite this, systems of criminal justice continue to be based to a large degree on judgments of moral blameworthiness. Forensic psychiatric evidence related to mental disorder has long been a part of assessing mental capacity and responsibility, and an intriguing question posed by the emerging biologically-oriented accounts of criminal behaviour is whether these biological accounts are more likely than the typical non-biological psychiatric evidence to reduce attributions of control and blame.

A growing body of experimental research is examining whether the effects of neurobiological explanations of criminal behaviour differ from those of psychiatric explanations. The results are inconsistent so far, perhaps reflecting the different methodologies adopted. ${ }^{62}$ One survey of nearly 200 American state trial judges found that evidence supporting a neurobiological cause of an offender's psychopathy reduced the sentence imposed as well as the extent to which the psychopathy was viewed as an

Joshua Greene \& Jonathan Cohen, "For the Law, Neuroscience Changes Nothing and Everything" (2004) 359 Philosophical Transactions Royal Society London 1775.

$60 \quad$ Ibid at 1783.

61 Christopher Slobogin, "The Civilization of the Criminal Law" (2005) 58:1Vand L Rev 121; Stephen J Morse, "Gene-Environment Interactions, Criminal Responsibility, and Sentencing" in Kenneth A Dodge \& Michael Rutter, eds, Gene-Environment Interactions in Developmental Psychopathology (New York: Guilford Press, 2011) 207; Anthony R Cashmore, "The Lucretian Swerve: The Biological Basis of Human Behavior and the Criminal Justice System" (2010) 107:10 Proceedings National Academy Sciences 4499.

62 Lisa G Aspinwall, Teneille R Brown \& James Tabery, “The Double-Edged Sword: Does Biomechanism Increase or Decrease Judges' Sentencing of Psychopaths?" (2012) 337 Science 846; Johannes Fuss, Harald Dressing \& Peer Briken, "Neurogenetic Evidence in the Courtroom: A Randomised Controlled Trial With German Judges" (2015) 52:11 J Medical Genetics 730; Benjamin Y Cheung \& Steven J Heine, "The Double-Edged Sword of Genetic Accounts of Criminality: Causal Attributions from Genetic Ascriptions Affect Legal Decision Making" (2015) 41:12 Personality \& Social Psychology Bulletin 1723; Paul S Appelbaum \& Nicholas Scurich, "Impact of Behavioral Genetic Evidence on the Adjudication of Criminal Behavior" (2014) 42:1 J American Academy Psychiatry \& L 91; Nicholas Scurich \& Paul Appelbaum, "The Blunt-Edged Sword: Genetic Explanations of Misbehavior Neither Mitigate Nor Aggravate Punishment" (2016) 3:1 JL \& Biosciences 140. 
aggravating factor. ${ }^{63}$ The judges considered a vignette in which a psychiatrist provided expert testimony that a man who committed a violent assault was a psychopath. Half of the participants also received the expert testimony of a neurobiologist who presented a neurobiological explanation of the psychopathy. The participants were able to provide explanatory comments on their responses. One judge wrote that " $\mathrm{t}] \mathrm{he}$ evidence that psychopaths do not have the necessary neural connections to feel empathy is significant. It makes possible an argument that psychopaths are, in a sense, morally 'disabled' just as other people are physically disabled." ${ }^{64}$ The neurobiological explanation of psychopathy appears to have reduced perceived moral blame but at the same time may have increased the perception of increased dangerousness. Another judge wrote that "[p]sychopathy may make the defendant less morally culpable, but it increases his future dangerousness to society. In my mind, these factors balance out." ${ }^{\prime \prime 5}$ In a similar study with a group of German judges, Fuss and colleagues found that the neurobiological explanation slightly reduced the judgment of legal responsibility, but it did not significantly affect the prison sentence imposed. However, the presentation of the neurobiological evidence by the prosecution did greatly increase the decision to order involuntary commitment in a psychiatric hospital, which could lead to a longer detention time.

As research in behavioural genetics and neuroscience proceeds, evidence suggesting biological causal influences on criminal behaviour will be identified. This evidence fits fairly seamlessly into existing sentencing practices in which a broad range of biological, social and environmental causes of behaviour are proposed in an attempt to mitigate blame. Another possibility is that biological causal explanations of behaviour may be more likely than other explanations to imply an offender is dangerous, producing an aggravating effect on sentencing decisions. As the scientific research is taken up by courts, key questions will be whether a neurobiological work-up is likely to improve legal decision-making or not, when it is likely to be in an offender's interest to pursue this type of evidence, and whether the right to make a full answer and defence might sometimes require the collection and presentation of this type of evidence.

\section{THE REgULATION OF BRAIN INTERVENTIONS: MIND-BRAIN DUALISM}

Biological psychiatry, and particularly the accumulation of information at the biological levels about mental illnesses, will challenge laws that purport to distinguish between the mind or mental properties on one hand, and the brain and its physical properties on the other hand. Put another way, biological psychiatry is monist (treating the mind and brain as aspects of the same thing) and also materialist (regarding mental states as reflections of states of physical matter). ${ }^{66}$ The law, on the other hand, is often dualistic, positing a distinction between mental and physical phenomena, or between psychiatric and neurological treatments. This dualism will be increasingly unstable as the neurobiological underpinnings of psychiatric disorders are discovered.

Aspinwall, Brown \& Tabery, ibid.

Ibid at 847 .

Ibid at 848 .

Gach, supra note 1 at 685 . 
A good example is furnished by section 49 of Ontario's Mental Health Act, which sets specific rules to govern "psychosurgery." ${ }^{\circ 7}$ The special and restrictive rules are explained by the backlash against the prefrontal lobotomy that garnered its inventor the 1949 Nobel prize, but went on to be applied in widespread and highly questionable ways in the mid-twentieth century. ${ }^{68}$ Section 49 states that psychosurgery cannot be administered to people who are incapable of consenting for themselves, as well as to people detained involuntarily in a psychiatric facility under mental health legislation or the Criminal Code. ${ }^{69}$ The purpose of this restriction is to protect people who are vulnerable by reason of incapacity or because they are being detained in a psychiatric facility.

However, it is the definition of "psychosurgery" that reveals the legal impact of biological psychiatry. The Act defines psychosurgery as follows:

49(2) Psychosurgery is any procedure that, by direct or indirect access to the brain, removes, destroys or interrupts the continuity of histologically normal brain tissue, or that inserts indwelling electrodes for pulsed electrical stimulation for the purpose of altering behaviour or treating psychiatric illness, but does not include neurological procedures used to diagnose or treat organic brain conditions, intractable physical pain or epilepsy, if these conditions are clearly demonstrable. ${ }^{70}$

This definition is a problem on many levels. First, it is not clear that those whose symptoms are due to demonstrable organic brain conditions are any less vulnerable than those whose symptoms are ascribed to a psychiatric condition. The definition thus fails to accord with the apparent objective of the legislation.

Second, how should we classify interventions that target the behavioural consequences of what is clearly an organic brain disorder? Should this be understood as an intervention to address an organic brain condition or an intervention to alter behaviour? For example, a surgical intervention to address intractable aggression after a traumatic brain injury will not remedy the brain injury but may address the behavioural consequence of that injury. ${ }^{71}$

Third, intractable physical pain is sometimes ascribed to psychiatric somatoform disorders, ${ }^{72}$ and so it is necessary to decide whether neurosurgical treatment of such cases should be excluded from the regulation as a "neurological procedure used to ... treat ... intractable physical pain," or included as a treatment for "psychiatric illness."

Finally, Ontario's dualistic definition of psychosurgery, which distinguishes psychiatric "mental" conditions and organic "brain" conditions is inherently unstable. In psychiatry, the "organic brain disorders" are understood to include "a range of mental disorders grouped together on the basis of their having in common a demonstrable etiology in cerebral disease,

Mental Health Act, RSO 1990 c M.7, s 49.

Elliot S Valenstein, Great and Desperate Cures: The Rise and Decline of Psychosurgery and Other Radical Treatments for Mental Illness (New York: Basic Books, 1986) at 4.

Mental Health Act, supra note 67, s 49(1).

Ibid.

See Marc Lévêque, Psychosurgery: New Techniques for Brain Disorders (Paris: Springer, 2014) at 230 for a discussion of the use of psychosurgery in aggressive disorders. Supra note 44 at 485 . 
brain injury, or other insult leading to cerebral dysfunction." ${ }^{, 73}$ Psychiatric conditions, on the other hand, are those mental and behavioural disorders that lack this demonstrable physical etiology. History is filled with examples of mental conditions that are now regarded as organic brain disorders, such as epilepsy, neurosyphilis, and certain vitamin deficiencies. As Insel and Quirion have noted, "[i]n the past, mental disorders were defined by the absence of a so-called organic lesion. Mental disorders became neurological disorders at the moment a lesion was found." 74

It is an explicit objective of today's biological psychiatry to uncover the biological nature of psychiatric conditions, and to find biomarkers that help to move away from nosologies based on symptoms to those based on underlying biology. If and when biomarkers are identified for other psychiatric conditions that are currently poorly understood, the category of "organic brain disorders" will grow and the scope of the regulation of "psychosurgery" will shrink.

\section{REgUlATION OF REPRODUCTIVE TECHNOLOGIES: THE "NEW EUGENICS"?}

Biological psychiatry is interested in understanding psychiatric disorders at multiple levels of biological focus spanning genes, molecules, cells, circuits, and structures in the brain. Some conditions such as aneuploidies like Down syndrome have a clear and determining genetic causal explanation. For other conditions, such as schizophrenia or bipolar disorder, heritability studies suggest a genetic contribution although causation is complex and multifactorial. ${ }^{75}$ If, and when, biological psychiatry uncovers these genetic contributions, and particularly if they are found to substantially raise the risk of developing mental illness, we may need to contend with what has come to be known as the "new eugenics" or the screening out of affected embryos or fetuses prior to birth.

There is no necessary association between a biological psychiatry and eugenic impulses. What matters is the social response to the mental condition in question. A society that devalues these conditions will respond differently from one that accommodates or celebrates the diversity in terms of mental and behavioural types. The neurodiversity movement, which originated with the autistic community and has now broadened to include a range of other conditions or "neurotypes," shows that a eugenic response is not a necessary result of biological psychiatry. ${ }^{76}$ However, one cannot ignore the connection between biological theories of mental disorders and the twentieth century state-sanctioned eugenic policies in multiple countries including Canada.

73 World Health Organization, "F00-F09 Organic, Including Symptomatic, Mental Disorders" in International Statistical Classification of Diseases and Related Health Problems, 10th revision(ICD-10) (2016), online: <apps.who.int/classifications/icd10/browse/2016/en\#/F00-F09>.

74 Thomas R Insel \& Remi Quirion, "Psychiatry as a Clinical Neuroscience Discipline" (2005) 294:17 J American Medical Assoc 2221 at 2221.

75 Kathleen Ries Merikangas \& Anibal Cravchik, "Contribution of Genetic Epidemiology to Our Understanding of Psychiatric Disorders" in John I Nurnberger \& Wade H Berrettini, eds, Principles of Psychiatric Genetics (Cambridge: Cambridge University Press, 2012) at 1.

76 Simon Baron-Cohen, "Neuroethics of Neurodiversity" in J Clausen \& N Levy, eds, Handbook of Neuroethics (Dordrecht: Springer, 2015) at 1757; Andrew Fenton \& Tim Krahn, "Autism, Neurodiversity and Equality Beyond the "Normal"” (2007) 2:2 J Ethics in Mental Health 1. 
As is well-known, eugenic ideologies led to programs of the most profound human rights violations in the twentieth century in Nazi Germany as well as in North America. These ideologies originated in the mid to late nineteenth century in the confluence of the social disruption caused by industrialization, the publication of Darwin's On the Origin of Species by Means of Natural Selection, and the rediscovery of Mendel's experiments on heredity. ${ }^{77}$ The idea of eugenics was to improve humanity through selective reproduction, much as was done with livestock. In 1934, the Nazis passed the "Law for the Prevention of Hereditarily Diseased Progeny" which forced sterilization of people diagnosed with a range of mental illnesses and cognitive disabilities. ${ }^{78}$ Similar laws were passed in Canada and the United States. Among the subsequent outrages committed by the Nazi government were the programs of "special treatment," namely, murder of children with mental disabilities and adults with mental illness and mental disabilities. ${ }^{79}$

Eugenic ideologies also drove law and policy in North America, where the objective of improving the fitness of the population led first to the idea of isolating or segregating those with mental illness and cognitive disabilities to prevent reproduction and then to the idea of contraceptive sterilization as a cheaper alternative. ${ }^{80}$ The constitutionality of the American state compulsory sterilization laws was upheld in Buck v. Bell ${ }^{81}$ and they remained in some places until the 1970s ${ }^{82}$ Canada, too, adopted legislation authorizing the forced contraceptive sterilization of people with mental illnesses. ${ }^{83}$ In fact, Alberta's 1928 Sexual Sterilization Act was the first of its kind in the British Commonwealth, allowing a Eugenics Board to authorize sterilization of those about to be discharged from mental institutions in order to eliminate the "danger of procreation with its attendant risk of multiplication of the evil by transmission of the disability to progeny." 84

Although these statutes have been repealed, and Alberta has apologized and paid compensation to some of those forcibly sterilized under its legislation, ${ }^{85}$ some have suggested that we are now in an era of "laissez-faire," "liberal," or "new" eugenics in which parents take up the tools of prenatal diagnosis and pre-implantation genetic diagnosis to avoid the birth of children at risk of particular condition. ${ }^{86}$ Prenatal screening for Down syndrome has been available since the early 1970s and is now commonplace, and the vast majority of cases diagnosed prenatally result in abortion. ${ }^{87}$

Bernard A Fischer, "Maltreatment of People with Serious Mental Illness in the Early 20th Century: A Focus on Nazi Germany and Eugenics in America" (2012) 200:12 J Nervous \& Mental Disease 1096; A Naomi Nind, "Solving an 'Appalling' Problem: Social Reformers and the Campaign for the Alberta Sexual Sterilization Act, 1928” (2000) 38:2 Alta L Rev 536 at 537.

Fischer, ibid.

Ibid.

Ibid.

Buck v Bell, 274 US 200 (1927).

Fischer, supra note 77; Nind, supra note 77

Sexual Sterilization Act, SA 1928, c 37. See also Muir v Alberta (1996), 132 DLR (4th) 695 (Alta QB). Nind, supra note 77 at 537, citing Sexual Sterilization Act, ibid, s 5.

“Alberta Apologizes for Forced Sterilization,” CBC News (9 November 1999), online: <www.cbc.ca/ news/canada/alberta-apologizes-for-forced-sterilization-1.169579>.

Nicholas Agar, "Liberal Eugenics" (1998) 12:2 Public Affairs Q 137; Timothy Caulfield \& Gerald Robertson, "Eugenic Policies in Alberta: From the Systematic to the Systemic?" (1996) 35:1 Alta L Rev 59.

87 Arthur L Caplan, “Chloe's Law: A Powerful Legislative Movement Challenging a Core Ethical Norm of Genetic Testing” (2015) 13:8 PLOS Biology 1. 
While the genetic contributions to most major mental health conditions are extremely complex, and are unlikely to be the complete etiological story, the identification of psychiatric genetic risk factors is likely to enter a new world in which mental health stigma, social structures, and economic constraints will put pressure on parents to avoid conditions perceived as disabling and costly.

A good example of the possible impact of these developments as psychiatric genetics develops is furnished by the recent application to the United Kingdom's Human Fertility and Embryology Authority (HFEA) to approve pre-implantation genetic screening for autism spectrum disorder (ASD). Pre-implantation genetic diagnosis (PGD) involves the testing of embryos created through in vitro fertilization to detect genes associated with various conditions. Under UK law, PGD may only be performed to detect conditions licenced by the HFEA. ${ }^{88}$ While this testing was developed for fully penetrant, monogenic, severe pediatric conditions, use has now expanded to a range of other heritable conditions. ${ }^{89}$

In 2014, the HFEA considered whether to approve an application to licence screening out male embryos to avoid the inheritance of ASD. ${ }^{90}$ The applicants argued that this should be available for families with at least two severely affected male children on the basis that ASD was a "gender-related serious medical condition." The Committee rejected the application because there was no "specific conclusive test for autism," and stated that applications could not be approved "unless and until there is more scientific certainty on the genetic cause(s) of Autism Spectrum Disorder." ${ }^{\text {"1 }}$ Despite the uncertain genetics of ASD, other jurisdictions such as the Australian States of Western Australia and Victoria have authorized the screening out of male embryos in families with a prior history of the condition. ${ }^{92}$

Research into the attitudes of families affected by mental health conditions toward hypothetical genetic tests shows some receptiveness to using them to avoid or terminate affected pregnancies. This is noteworthy given that these families are likely to be better informed about the reality of living with these conditions than the general public. A recent study of the attitudes of parents of children with ASD toward prenatal genetic testing and pregnancy termination found that 57 percent of the 42 participating parents would use a hypothetical prenatal test for autism, and 20 percent of the group that was willing to take the test or unsure about taking the test said they would have terminated affected pregnancies. ${ }^{93}$ Research into the attitudes of extended families affected by multiple cases of bipolar disorder to a hypothetical genetic test for the condition showed 54 percent endorsed prenatal testing, and 27 percent endorsed termination if the test indicated that bipolar disorder would

88 UK, Human Fertility and Embryology Authority, "PGD Conditions Licensed by the HFEA," online: $<$ guide.hfea.gov.uk/pgd/>.

89 Kristopher J Abbate et al, "Views of Preimplantation Genetic Diagnosis (PGD) Among Psychiatrists and Neurologists" (2014) 59 J Reproductive Medicine 385.

90 UK, Human Fertility and Embryology Authority, "Minutes: 30 January 2014," PGD Application for Autism Spectrum Disorder OMIM \#209850 (London: HFEA, 2014), online: < guide.hfea.gov.uk/guide/ ShowPDF.aspx?ID=5518>.

$91 \quad$ Ibid at para 18.

$92 \quad$ Ari Ne'eman, "Screening Sperm Donors for Autism? As an Autistic Person, I Know that's the Road to Eugenics," The Guardian (30 December 2015), online: <www.theguardian.com/commentisfree/2015/ $\mathrm{dec} / 30 /$ screening-sperm-donors-autism-autistic-eugenics $>$.

$93 \quad$ LS Chen et al, "Autism Spectrum Disorders: A Qualitative Study of Attitudes Toward Prenatal Genetic Testing and Termination Decisions of Affected Pregnancies" (2015) 88 Clinical Genetics 122. 
definitely develop. ${ }^{94}$ Among those diagnosed with a psychiatric condition, 25 percent endorsed termination, and among unaffected family members, 29 percent endorsed termination.

This research supports the suggestion of Lakhan and colleagues that "[i]t is only a matter of time before psychiatric biomarkers are added to the list of conditions routinely screened for prenatally." ${ }^{95}$ Whether or not these screening tests are likely to lead to abortion probably depends upon the predictive value of the test, as well as on whether the condition itself varies in severity (as is the case with ASD). Nevertheless, it is important to note that the move toward embryo screening prior to implantation, and even to gene editing of affected embryos, avoids the likely more difficult decision of whether to terminate an established pregnancy.

Biological psychiatry intersects here with the law by raising the challenging issue of whether regulatory regimes should attempt to limit the use of prenatal or pre-implantation genetic diagnosis, as is done in the UK, or leave decision-making to parents and clinicians. This contentious issue pits concerns about the devaluation and disappearance of certain classes of people through a form of new eugenics against the reproductive liberty of parents. The debate is likely to become only more difficult with the increasing understanding of psychiatric genetics.

\section{CONCLUSION}

Biological theories of mental illness are not new, although they are increasing in sophistication. There are many reasons to celebrate this new knowledge, particularly as better understanding of all of the causal contributions to mental illnesses (psychosocial and biological) will help in designing preventive strategies and more effective ways to help. At the same time, biological psychiatry seems to encourage certain patterns of thought that have social, political, and legal consequences. These consequences may be helpful or harmful, or perhaps both, as the example of how the brain disease model of mental illness both increases and decreases different components of stigma shows. The ultimate ideological consequences of biological psychiatry on the law and other social institutions are difficult to predict. Attention to these topics over the coming years is advisable in order to ensure the benefits of the accumulating knowledge are seized and the social, political, and economic risks are avoided. 